COPYRIGHT @ 2013 INTERNATIONAL JOURNAL OF SCIENCE DENTISTRY | AVAILABLE ONLINE http://www.periodicos.uff.br/index

\title{
A ORTOPEDIA FUNCIONAL COMO POSSIBILIDADE TERAPÊUTICA PARA TRATAMENTO DA MALOCLUSÃO NA DOENÇA FALCIFORME
}

José Magalhães Muniz Filho - Graduado em Odontologia, Faculdade de Odontologia de Nova Friburgo, RJ, Brasil

Priscila Ladeira Casado

Professora Adjunta - PhD em Morfologia - Faculdade de Odontologia - Universidade Federal Fluminense, Niterói, RJ, Brasil

Endereço para Correspondência:

Rua Mario Santos Braga, 28 Centro, Niterói

Campus do Valonguinho

CEP :24020-140 E-mail: plcasado@ hotmail.com

Categoria: Artigo de Revisão

Palavras-chave: Anemia falciforme; Ortopedia funcional; Odontologia; Maloclusão.

Key Words: Sickle cell; Functional orthopedics; Dentistry; Malocclusion. 
COPYRIGHT @ 2013 INTERNATIONAL JOURNAL OF SCIENCE DENTISTRY | AVAILABLE ONLINE

http://www.periodicos.uff.br/index

\section{INTRODUÇÃO}

A ortopedia funcional como possibilidade terapêutica para tratamento da maloclusão na doença falciforme vem sedo observada como uma relação amplamente positiva, onde os resultados podem ser traduzidos com um processo de conquistas ofertados pela odontologia.

A Ortopedia Funcional dos Maxilares é uma especialidade da Odontologia que tem por objetivo monitorar o desenvolvimento da oclusão, colaborando com a harmonia de desenvolvimento e corrigindo os desvios da função oclusal. Sua atuação utiliza recursos próprios os quais incluem aparelhos em dentes decíduos ou permanentes, ajustes oclusais por desgastes ou ajustes oclusais por acréscimo de resinas em dentes decíduos (LENTINI-OLIVEIRA et al., 2005).

Ao estudar a doença falciforme, o primeiro ponto a ser identificado é que esta é uma das enfermidades genéticas e hereditárias mais comum no mundo. A causa da anemia falciforme é uma mutação no gene que produz a hemoglobina A ( $\mathrm{HbA}$ ), originando outro mutante: a hemoglobina S, uma herança recessiva (BRASIL, 2014). A figura 01 esclarece essa relação:

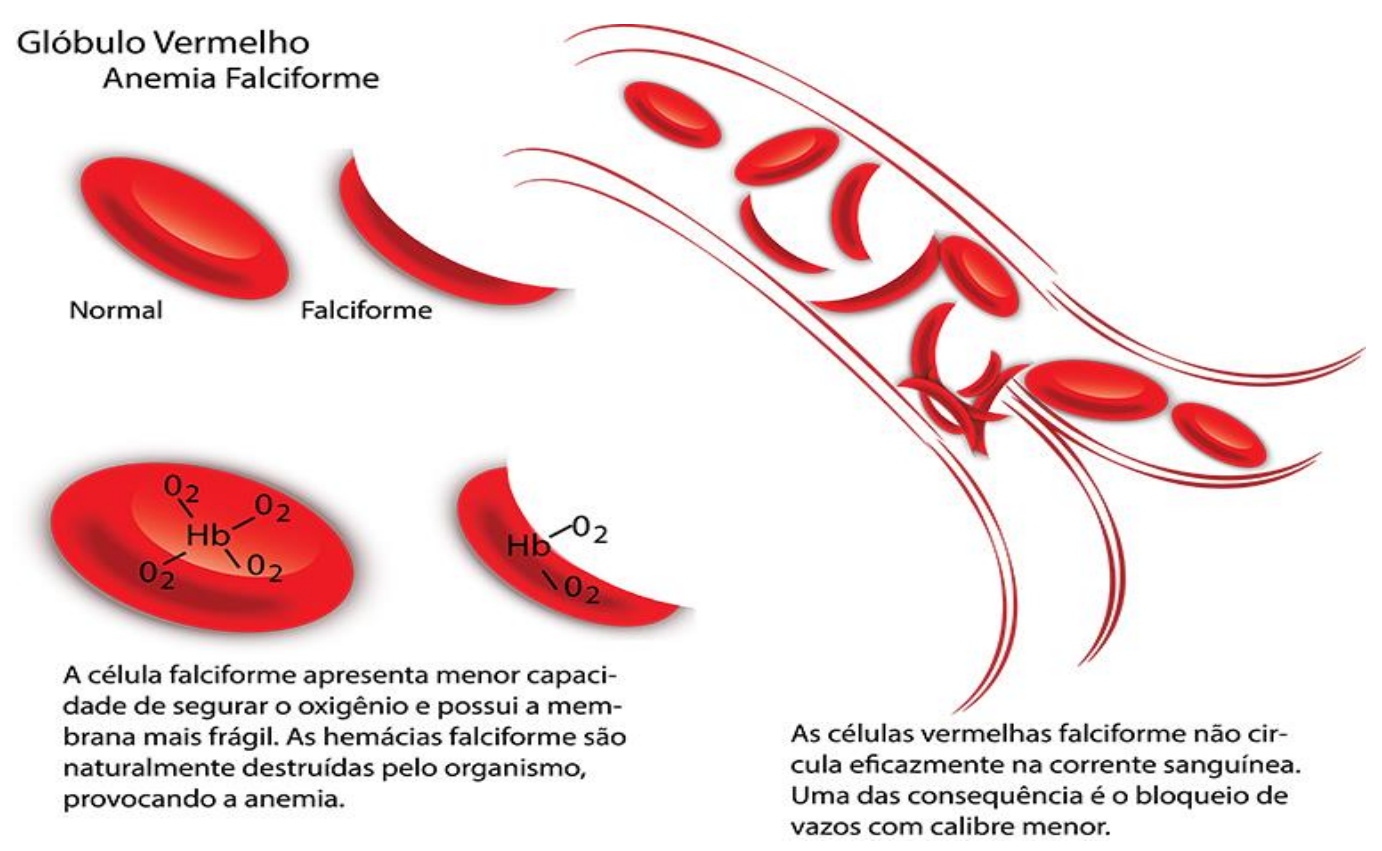

Figura 01: Glóbulos vermelhos e a anemia falciforme - Fonte: Complexo HUPES

Assim, pode-se compreender que a anemia falciforme, também chamada de siclemia ou depranocitose é uma doença hereditária, mais prevalente no gênero feminino, ocasionada por uma mutação no gene da globina beta da hemoglobina, resultando na substituição de um ácido glutâmico por uma valina na posição 6 da cadeia beta da hemoglobina, originando uma hemoglobina anormal, denominada $\mathrm{Hbs}$ (BRASIL, 2014).

É pertinente sinalizar que a anemia falciforme é uma doença crônica incurável, contudo, tratável. Ou seja, os avanços no conhecimento de novos aspectos moleculares, 
COPYRIGHT @ 2013 INTERNATIONAL JOURNAL OF SCIENCE DENTISTRY | AVAILABLE ONLINE

http://www.periodicos.uff.br/index

celulares e clínicos da doença falciforme confirmam que se trata de uma doença inflamatória crônica permeada de episódios agudos clinicamente controláveis (CANÇADO e JESUS, 2007).

Salienta-se que a anemia falciforme também tem sido considerada como um importante fator associado a alterações bucais, tais como, atraso na erupção dentária, periodontite, língua lisa, descorada e despapilada, hipomaturação e hipomineralização do esmalte e dentina, hipercementose, osteomielite, necrose pulpar entre outras (BOTELHO et al., 2009).

No tocante ao tratamento odontológico, acrescenta-se ainda algumas características que podem ser encontradas nas radiografias periapicais de indivíduos com anemia de células falciformes, incluindo a formação de um padrão trabeculada espessura, atribuída à hiperplasia eritrobltica e hipertrofia medular que resultam na perda do osso trabeculada fina e formação de largura (PITHON, 2011).

Assim, o presente artigo tem como objetivo apresentar uma revisão da literatura sobre a terapia ortodôntica na doença falciforme.

Para além, cabe evidenciar que a temática sobre o tratamento dos pacientes com anemia falciforme a partir terapia ortodôntica se traduz como atual e ainda pouco explorada, tanto pelo meio acadêmico como pelo meio profissional.

\section{REVISÃO DE LITERATURA}

A anemia é uma doença do transporte de oxigênio, sendo que os tecidos supridos pela circulação recebem quantidades deficientes de oxigênio. Esse processo pode ser decorrente da redução do número de eritrócitos, da quantidade diminuída de hemoglobina, ou por defeitos na molécula da hemoglobina (BOTELHO et al., 2009).

Pithon (2011) destaca-se que a hemoglobina é uma proteína respiratória nos eritrócitos com a função principal de transporte de oxigênio em todo o corpo. A biologia molecular explica a anemia falciforme como uma mutação da hemoglobina que conduz a células que se assemelham com foice, conforme pode ser observado na figura 02:
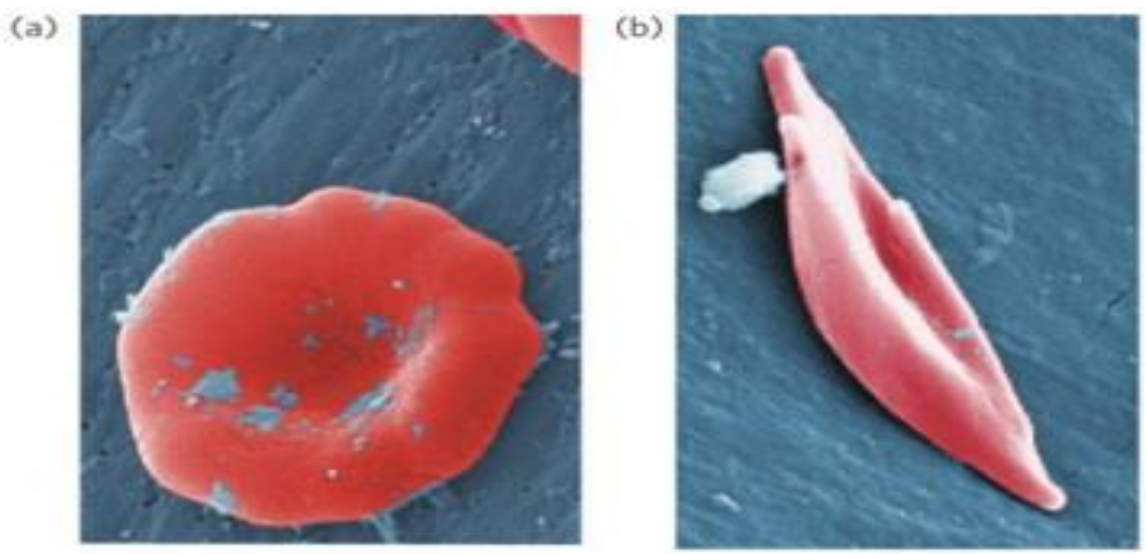

(a) Eritrócito normal uniforme; (b) Eritrócito em forma de foice observado na anemia falciforme.

Figura 02: Eritrócitos - Fonte: COX et al., 2012.

REVISTA FLUMINENSE DE ODONTOLOGIA - ANO XIX - No 40 - Julho / Dezembro 2013 
COPYRIGHT @ 2013 INTERNATIONAL JOURNAL OF SCIENCE DENTISTRY | AVAILABLE ONLINE http://www.periodicos.uff.br/index

Indo além, como forma de compreender sobre a oxigenação e as moléculas de hemoglobina, pode-se ainda destacar que em situações de baixa tensão de oxigênio, as moléculas de hemoglobina afetadas alteraram a sua forma, a partir de disco normal para a forma de uma foice. Inicialmente, quando o nível de oxigênio aumenta, esta falcização é reversível; no entanto, as constantes mudanças de forma das células vermelhas do sangue tendem a prejudicar suas membranas celulares, que se tornam rígidas e não mais retornar ao seu estado normal (PITHON, 2011).

Neste contexto, é possível identificar que a anemia falciforme (HbSS) é causada pela mutação no gene da globina beta da hemoglobina, originando uma hemoglobina alterada denominada hemoglobina $S$, que pode se polimerizar e promover a falcização das hemácias quando em homozigose (BOTELHO et al., 2009).

As crianças apresentam histórico de múltiplas hospitalizações por crises de dor, episódios de anemia severa, múltiplas transfusões sanguíneas e períodos recorrentes de infecções pulmonares (SOARES et al., 2010).

Ainda dentro deste universo, a anemia falciforme tem sido considerada como um importante fator associado às alterações bucais, tais como: Atraso na erupção dentária; Periodontite, língua lisa, descorada e despapilada; Hipomaturação e hipomineralização do esmalte e dentina; Hipercementose; Osteomielite; Necrose pulpar entre outras (BOTELHO et al., 2009).

Esta doença hematológica hereditária comum afeta muitos sistemas e tecidos do corpo, incluindo a boca, erupção atrasada de dente, um grau incomum de periodontite, alterações nas células da superfície da língua, hipomaturação e hipomineralização em esmalte e dentina, hipercementose e alterações ósseas, resultando em protrusão maxilar e formação de um padrão trabecular grossa são algumas manifestações orais da doença (PITHON, 2011). Neste contexto, pode-se observar a figura 03, que retrata algumas alterações citadas:
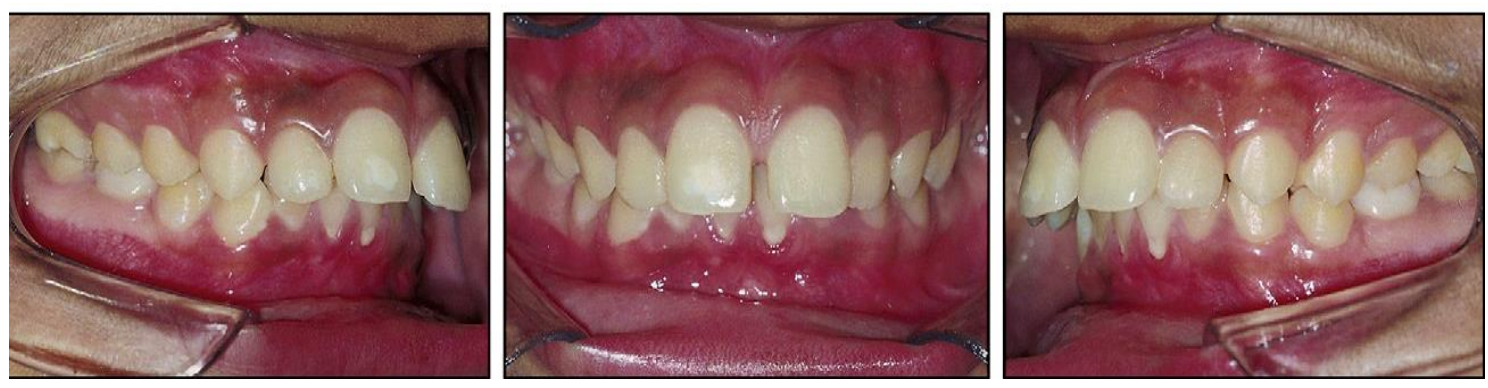

Figura 03: Protrusão Maxilar; hipomineralização em esmalte e dentina. Fonte: PITHON, 2011.

A Ortopedia Funcional proporciona melhor qualidade de vida aos pacientes falcêmicos através de redução de incidência de complicações respiratórias, estimula o cuidado com a saúde bucal para reduzir incidência de dentes cariados e extrações, promove um equilíbrio estético facial e corporal que levem à melhora da auto-estima e está de acordo com a Política Nacional de Atendimento Integral às Pessoas Portadoras de Doença Falciforme (BRASIL, 2005).

REVISTA FLUMINENSE DE ODONTOLOGIA - ANO XIX - No 40 - Julho / Dezembro 2013 
COPYRIGHT @ 2013 INTERNATIONAL JOURNAL OF SCIENCE DENTISTRY | AVAILABLE ONLINE

http://www.periodicos.uff.br/index

É notório que o tratamento ortopédico funcional possibilita o restabelecimento de uma boa oclusão de arcada dentária, tendo como consequência um melhor padrão respiratório com redução de deformidades de caixa torácica e redução da incidência de cáries (SÁ FILHO, 1994).

Os pacientes com anemia falciforme devem ser acompanhados em centros de referência especializados capazes de oferecer atendimento global, multidisciplinar e multiprofissional (CANÇADO e JESUS, 2007).

Botelho et al. (2009) complementam que a anemia falciforme é uma doença complexa com repercussões sistêmicas, sem sinais patognomônicos e de caráter endêmico na população. Com essas características peculiares, torna-se extremamente necessário que o cirurgião dentista detenha o conhecimento sobre o perfil sistêmico e bucal dos portadores da siclemia ou depranocitose, e nesta direção cabe verificar a tabela 01:

Tabela 01: Características sistêmicas e orais do pacientes com anemia falciforme Fonte: (SOARES et al., 2010).

- Diastemas múltiplos;

- Atraso na erupção dentária;

- Hipoplasia da dentição secundária;

- Hipercementose;

- Transtornos na mineralização do esmalte;

- Alterações nas células da superfície da língua;

- Máloclusão, caracterizada por protrusão maxilar;

- Retrusão de dentes anteriores.

No que tange ao tratamento, com foco no cenário da odontologia, cabe evidenciar que a época ideal para os cuidados com a ortopedia funcional é de 4 a 12 anos de idade. O tratamento ortodôntico corretivo, em geral, deve ocorrer no período da pré-adolescência (BRASIL, 2014).

Outro recorte feito acerca do início do tratamento com a odontologia é sobre o momento ideal para começar a tratar das meninas, uma vez que é aconselhável que este processo ocorra próximo à menarca. Como nas pessoas com doença falciforme pode haver um atraso no desenvolvimento da idade óssea e na maturação sexual, o momento correto para iniciar o tratamento ortodôntico ficará um pouco atrasado, em comparação com as pessoas que não apresentam a doença. Assim como, confirmar o caso com documentação radiológica de punho e de mão, o que auxilia a determinar o momento ideal (BRASIL, 2014).

REVISTA FLUMINENSE DE ODONTOLOGIA - ANO XIX - No 40 - Julho / Dezembro 2013 
COPYRIGHT @ 2013 INTERNATIONAL JOURNAL OF SCIENCE DENTISTRY | AVAILABLE ONLINE http://www.periodicos.uff.br/index

Ao usar o aparelho ortopédico funcional dos maxilares o paciente tende a apresentar melhora na qualidade respiratória, ou seja, o tratamento tem o intuito de superar e/ou amenizar os problemas de oxigenação que os pacientes tendem a enfrentar no seu cotidiano. Indo além, o referido tratamento também tende a oportunizar benefício à estética e a auto-estima do paciente (LENTINI-OLIVEIRA et al., 2005).

No que se refere asmaloclusões, deve-se destacar que freqüentemente estas são resultado da combinação de diferentes fatores dentro de um potencial de crescimento inerente a cada indivíduo e, portanto, são multifatoriais. Diversos artigos apontam que as maloclusões têm sido associadas com a respiração bucal em crianças (LENTINIOLIVEIRA et al., 2005)..

Como forma de explicar sobre a relação da maloclusão com a doença falciforme, pode-se descrever que as alterações ósseas são comuns em pacientes portadores da doença, nos quais podem ser observadas mudanças tanto na maxila quanto na mandíbula que consistem geralmente na diminuição da radiodensidade e na formação de um trabeculado grosseiro, atribuído à hiperplasia eritroblástica e hipertrofia medular que resulta em perda do fino trabeculado ósseo e na formação de largos espaços medulares (LENTINI-OLIVEIRA et al., 2005).

\section{DISCUSSÃO}

A anemia falciforme interfere no desenvolvimento de ossos e dentes, por isso, quanto mais precoce é o seu diagnóstico, mais cedo é possível instituir medidas preventivas na Odontologia (SOARES et al, 2010).

É necessário ter em mente a importância de uma abordagem clínica eficiente, que possa atender às necessidades de cada paciente. Assim, o cirurgião dentista deve compreender as implicações da anemia falciforme para a eficiência e segurança no tratamento (SOARES et al, 2010).

Os pacientes falciformes devem ser mantidos em permanente controle e manutenção, sendo as medidas preventivas importantes para minimizar as consequências da doença, pois as infecções dentárias podem precipitar as crises e, consequentemente, contribuir para o desgaste da sua saúde geral (RODRIGUES et al., 2013).

De forma ampla, a referida doença tende a provocar alto grau de sofrimento aos seus portadores, e a partir desta perspectiva é sinalizado que tais pacientes merecem atenção especial do ponto de vista médico, odontológico, genético e psicossocial (RODRIGUES et al., 2013).

Neste sentido, o cirurgião-dentista como integrante de um grupo multidisciplinar e multiprofissional, exerce uma função importante no que se refere ao diagnóstico da doença falciforme, através dos exames clínico, radiográfico e laboratorial, colaborando para que sejam tomadas condutas que visem um prognóstico mais favorável da doença (RODRIGUES et al., 2013).. 
COPYRIGHT @ 2013 INTERNATIONAL JOURNAL OF SCIENCE DENTISTRY | AVAILABLE ONLINE

http://www.periodicos.uff.br/index

De forma geral, a literatura vem demonstrando a importância de o cirurgiãodentista ser inserido nas equipes multidisciplinares para exercerem o seu papel preventivo, curativo, de diagnóstico e de educação em saúde (SOARES et al, 2010).

Dando ênfase ao papel desenvolvido pelo cirurgião dentista pode-se enfatizar que este desempenha um papel importante na prevenção das complicações e na melhoria da qualidade de vida do paciente. Ademais, é possível afirmar que os ortodontistas devem ter conhecimento das manifestações orais e possíveis interferências da anemia falciforme em tratamento ortodôntico (PITHON, 2011).

Ainda evidencia-se que para o tratamento ortodôntico adequado, é indispensável conhecer o histórico médico de um paciente com doença falciforme, bem como a sua história familiar, para adquirir conhecimento do grau de comprometimento sistêmico da doença (PITHON, 2011).

Em suma, a relação da ortopedia funcional como possibilidade terapêutica para tratamento da maloclusão na doença falciforme oportuniza a melhoria da qualidade de vida aos pacientes com anemia falciforme a partir do tratamento ortopédico funcional dos maxilares, através da redução das internações por problemas respiratórios relacionados, dores faciais pelo equilíbrio da respiração e estimulo adequado a musculatura orofacial, ganho estético contribuindo na estima.

\section{CONCLUSÃO}

A ortopedia funcional pode ser compreendida como uma possibilidade viável para tratamento da maloclusão na doença falciforme

Todo o tratamento da anemia falciforme é apenas voltado para o controle dos sintomas por ela ocasionados, e neste sentido, o tratamento odontológico busca melhor qualidade de vida do paciente ao ofertar a utilização do aparelho ortopédico funcional, reduzindo os níveis de internação por problemas respiratórios comumente enfrentados por esses pacientes.

\section{REFERÊNCIAS}

BOTELHO, D.S.; VERGNE, A.A.; BITTENCOURT, S., RIBEIRO, E.D.P. Perfil sistêmico e conduta odontológica em pacientes com anemia falciforme.Int $\mathrm{J}$ Dent, Recife, 8(1): 28-35, jan./mar.,2009.

BRASIL. Portaria 1391, de 16 de agosto de 2005. Institui no âmbito do SUS as Diretrizes para a Política Nacional de Atenção Integral às Pessoas com Doença Falciforme e outras Hemoglobinopatias.

Ministério da Saúde. Doença falciforme: saúde bucal: prevenção e cuidado. Secretaria de Atenção à Saúde, Departamento de Atenção Hospitalar e de Urgência Brasília: Ministério da Saúde, 2014. 
COPYRIGHT @ 2013 INTERNATIONAL JOURNAL OF SCIENCE DENTISTRY | AVAILABLE ONLINE

http://www.periodicos.uff.br/index

CANÇADO, R.D.; JESUS, J. A. A doença falciforme no Brasil Rev. bras.hematol. hemoter. 2007; 29(3):203-206 .

COMPLEXO HUPES. Pesquisa de Ortopedia aplicada células tronco no tratamento para pacientes com anemia falciforme. Publicado em: 3 de fevereiro de 2015. Disponível em: http://www.complexohupes.ufba.br/noticias/pesquisa-de-ortopediaaplica-celulas-tronco-no-tratamento-para-pacientes-com-anemia-falciforme/ Acesso em: 03-03-2016.

COX, Michael M. [et al.]. Biologia molecular: princípios e práticas. Porto Alegre: Artmed, 2012.

LENTINI-OLIVEIRA, D.A.; CARVALHO, F.R.; MACHADO, M.A.C.; PRADO, L.B.F.; PRADO, G.F. Ortopedia funcional dos maxilares, respiração bucal e distúrbios respiratórios do sono em crianças. Revista Neurociências v13 n2 - abr/jun, 2005.

PITHON, M.M. Orthodontic treatment in a patient with sickle cell anemiaAmerican Journal of Orthodontics and Dentofacial Orthopedics. vol 140, Issue 5, November, 2011.

RODRIGUES, M.J.; MENEZES, A.; LUNA, A.C.A. Saúde bucal em portadores da anemia falciforme RGO - Rev Gaúcha Odontol., Porto Alegre, v.61, suplemento 0, p. 505-510, jul./jdez., 2013.

SÁ FILHO, F.P.G. As Bases Fisiológicas da Ortopedia Maxilar. Editora Santos,1994.

SOARES, F.F.; ROSSI, T.R.A, BRITO, M.G.S., VIANNA, M.I.P., CANGUSSU, M.C.T Condições de saúde bucal e fatores sociodemográficos de crianças de 6 a 96 meses com doença falciforme no Estado da BahiaRevOdontol UNESP, Araraquara. mar./abr., 2010; 39(2): 115-121. 